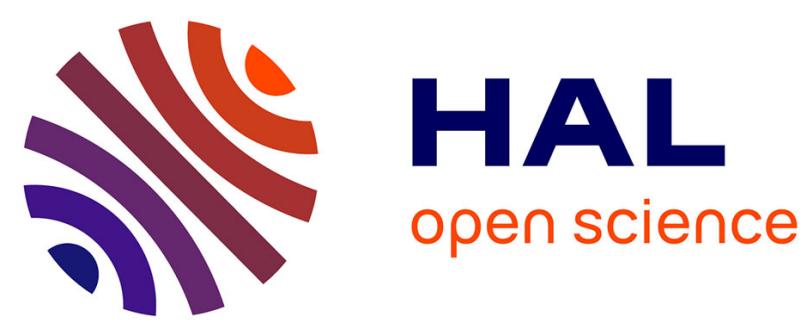

\title{
Fault Tolerant Strategy for Semi-Active Suspensions with LPV Accommodation
}

\author{
Juan C. Tudon-Martinez, Sébastien Varrier, Olivier Sename, Ruben Morales \\ Menendez, John Jairo Martinez Molina, Luc Dugard
}

\section{To cite this version:}

Juan C. Tudon-Martinez, Sébastien Varrier, Olivier Sename, Ruben Morales Menendez, John Jairo Martinez Molina, et al.. Fault Tolerant Strategy for Semi-Active Suspensions with LPV Accommodation. SysTol 2013 - 2nd International Conference on Control and Fault-Tolerant Systems, Oct 2013, Nice, France. hal-00937234

\section{HAL Id: hal-00937234 https://hal.science/hal-00937234}

Submitted on 28 Jan 2014

HAL is a multi-disciplinary open access archive for the deposit and dissemination of scientific research documents, whether they are published or not. The documents may come from teaching and research institutions in France or abroad, or from public or private research centers.
L'archive ouverte pluridisciplinaire HAL, est destinée au dépôt et à la diffusion de documents scientifiques de niveau recherche, publiés ou non, émanant des établissements d'enseignement et de recherche français ou étrangers, des laboratoires publics ou privés. 


\title{
Fault Tolerant Strategy for Semi-Active Suspensions with $L P V$ Accommodation *
}

\author{
Juan C. Tudón-Martínez ${ }^{1}$, Sébastien Varrier ${ }^{1}$, Olivier Sename ${ }^{1}$ \\ Ruben Morales-Menendez ${ }^{2}$, John-Jairo Martinez ${ }^{1}$ and Luc Dugard ${ }^{1}$
}

\begin{abstract}
A novel fault tolerant strategy to compensate multiplicative actuator faults (damper oil leakages) in a semiactive suspension system is proposed. The compensation of the lack of damping force caused by a faulty damper is carried on by the remainder three healthy semi-active dampers. Once a faulty damper is detected and isolated by a Fault Detection and Isolation strategy based on parity-space, an estimator is activated to compute the missing damping force to compensate. In order to fulfill the semi-active damper constraints, the fault accommodation is based on the Linear-Parameter Varying $(L P V)$ control strategy. Thus, each corner has a fault estimator and an $L P V$ controller oriented to comfort and road holding. Simulation results show that the proposed fault tolerant semiactive suspension improves the vehicle comfort up to $60 \%$ with respect to a controlled suspension without fault-tolerant strategy and $82 \%$ with respect to a passive suspension.
\end{abstract}

\section{INTRODUCTION}

Because the automotive industry demands safer and more comfortable vehicles constantly, the development of intelligent suspension systems has gained importance during last years. Semi-active dampers are efficient actuators to improve passengers comfort and car road holding as well [1]. However, as it shown in recent studies [1], [2], the control design for such dampers is complex due to the dissipativity constraint on the damper (which is indeed a state dependent saturation [3]).

Semi-active dampers allow the development of novel techniques to model, monitor and control an intelligent suspension system with fault-tolerance features to improve the process reliability. A Fault-Tolerant Controller (FTC) in a suspension system is designed to maintain the desired comfort and road holding performances as much as possible when a fault occurs. There are two main groups of FTC: passive (off-line designed) and active (on-line control reconfiguration mechanism); this study is focused on an active FTC because of its lower conservatism than a passive approach.

Active systems on-line utilize some fault information to compensate the fault effect by using a Fault Detection and Isolation $(F D I)$ strategy that can be model-based or databased. FDI modules based on analytical redundancy are the most accepted strategies for fault estimation [4], in particular

\footnotetext{
* This work was partially supported by CONACyT through the PCP project 03/10 FLORE and the French national project INOVE/ANR 2010 BLAN 0308.

${ }^{1}$ J.C. Tudón-Martínez, S. Varrier, O. Sename, J.J. Martínez and L. Dugard are with Gipsa-Lab, 11 rue des mathématiques, 38402 Grenoble, France juan-carlos.tudon@gipsa-lab.grenoble-inp.fr

${ }^{2} \mathrm{R}$. Morales-Menendez is with Tecnológico de Monterrey, Campus Monterrey, Av. Garza Sada 2501, 64849 Monterrey NL, México rmmeitesm.mx
}

parity-space approaches, e.g. [5] presents a fault signature of an intelligent damper by using parity relations.

During last years, the Linear Parameter-Varying ( $L P V)$ systems have gained importance as a solution to develop embedded control strategies for complex systems, e.g. the nonlinear vehicle dynamics, [6]. Recently, $L P V$-based techniques have been incorporated to FTC approaches, where additive faults are considered as a varying parameter to be accommodated by a scheduling reconfiguration approach, [7]. Based also on a scheduling reconfiguration, [8] proposed an active FTC using Sliding Mode observers. Both proposals lead to interesting results for a full vehicle but they are developed for active suspensions without actuator constraints. For semiactive suspensions, the authors have proposed in [9] an active FTC ( $L P V$-based) for additive actuator faults in a Quarter of Vehicle $(Q o V)$ model. The reconfiguration depends on the fault estimation, but a saturation constraint is needed.

As an extension of [9], this paper proposes an active FTC for a full vehicle semi-active suspension, when one of the dampers suffers an oil leakage (multiplicative actuator fault). The main contribution is the development of a new 2-level reconfiguration strategy that compensates a damper leakage by using the healthy dampers; because the force is inherently limited by the shock absorbers, an $L P V$ control design includes a saturation constraint on the compensation force used to the fault accommodation. At a higher level, 1) an FDI module identifies the faulty damper by using a parity-space approach and 2) the compensation forces are computed. At a lower level, each corner has a fault estimator and an $L P V$ based controller which also satisfies the dissipativity constraint of a commercial Magneto-Rheological $(M R)$ damper.

The paper is organized as follows: the problem statement is described in the next section. Sections III and IV describe the fault detection and estimation methodology and the FTC design, respectively. Section V presents the simulation results. Finally, conclusions are presented in section VI.

\section{Problem Statement}

A seven degrees of freedom model of the vertical dynamics of a full vehicle, including a semi-active suspension system, is considered as [10]:

$$
\begin{aligned}
m_{s} \ddot{z}_{s_{c}} & =-\left(F_{s_{1}}+F_{s_{2}}+F_{s_{3}}+F_{s_{4}}\right) \\
I_{x x} \ddot{\theta} & =\left(F_{s_{1}}-F_{s_{2}}\right) t_{f}+\left(F_{s_{3}}-F_{s_{4}}\right) t_{r} \\
I_{y y} \ddot{\phi} & =\left(F_{s_{4}}+F_{s_{3}}\right) l_{r}-\left(F_{s_{2}}+F_{s_{1}}\right) l_{f} \\
m_{u s_{i}} \ddot{z}_{u s_{i}} & =F_{s_{i}}-F_{t_{i}}
\end{aligned}
$$


where the vertical suspension force at each corner $\left(F_{s_{i}}\right.$, with $i=1, \ldots, 4$ ) is composed by the spring (stiffness $k_{s_{i}}$ ) and the semi-active damping force $\left(F_{s a_{i}}\right)$, as:

$$
F_{s_{i}}=k_{s_{i}}\left(z_{s_{i}}-z_{u s_{i}}\right)+F_{s a_{i}}
$$

while the tire vertical force, with stiffness $k_{t_{i}}$, is given by:

$$
F_{t_{i}}=k_{t_{i}}\left(z_{u s_{i}}-z_{r_{i}}\right)
$$

The semi-active force is modeled following [11], [12], as:

$$
F_{s a_{i}}=\underbrace{b_{1}\left(\dot{z}_{s_{i}}-\dot{z}_{u s_{i}}\right)+b_{2}\left(z_{s_{i}}-z_{u s_{i}}\right)}_{F_{p_{i}}}+F_{I_{i}}(I)
$$

$F_{I_{i}}(I)=I \cdot f_{c} \cdot \tanh \left[a_{1}\left(\dot{z}_{s_{i}}-\dot{z}_{u s_{i}}\right)+a_{2}\left(z_{s_{i}}-z_{u s_{i}}\right)\right](4 \mathrm{~b})$ where $I$ is the electric current and $F_{I_{i}}$ is the controlled semiactive force to improve the comfort and/or maintain the road holding. Note that for $I=0, F_{s a_{i}}$ reduces to the passive damping force $F_{p_{i}}$ of the suspension system. The sprung mass positions and velocities at each corner can be linearly derived from the vehicle dynamics, at small $\phi$ and $\theta$, as:

$$
\begin{array}{ll}
z_{s_{1}} \approx z_{s_{c}}+l_{f} \phi-t_{f} \theta & z_{s_{3}} \approx z_{s_{c}}-l_{r} \phi-t_{r} \theta \\
z_{s_{2}} \approx z_{s_{c}}+l_{f} \phi+t_{f} \theta & z_{s_{4}} \approx z_{s_{c}}-l_{r} \phi+t_{r} \theta \\
\dot{z}_{s_{1}} \approx \dot{z}_{s_{c}}+\dot{\phi} l_{f}-\dot{\theta} t_{f} & \dot{z}_{s_{3}} \approx \dot{z}_{s_{c}}-\dot{\phi} l_{r}-\dot{\theta} t_{r} \\
\dot{z}_{s_{2}} \approx \dot{z}_{s_{c}}+\dot{\phi} l_{f}+\dot{\theta} t_{f} & \dot{z}_{s_{4}} \approx \dot{z}_{s_{c}}-\dot{\phi} l_{r}+\dot{\theta} t_{r}
\end{array}
$$

\begin{tabular}{|c|c|c|}
\hline Parameter/Variable & Description & Value \\
\hline$\overline{a_{1,2}}$ & $M R$ damping coefficients & $37.8 \mathrm{~s} / \mathrm{m} \mathrm{\&} 22.1 \mathrm{~m}^{-1}$ \\
\hline$b_{1,2}$ & Passive damping coefficients & $2,830 \mathrm{Ns} / \mathrm{m} \&-7,897 \mathrm{~N} / \mathrm{m}$ \\
\hline$f_{c}^{\prime}$ & $M R$ dynamic yield force & $600.9 \mathrm{~N} / \mathrm{A}$ \\
\hline$I_{x x}, I_{y y}$ & Roll and pitch inertia & $844 \& 4434 \mathrm{Kg} \cdot \mathrm{m}^{2}$ \\
\hline$k_{s_{1,2}}, k_{s_{3,4}}$ & Front and rear spring stiffness & $43,500 \& 39,300 \mathrm{~N} / \mathrm{m}$ \\
\hline$k_{t_{1,2,3,4}}$ & Tire stiffness & $230,000 \mathrm{~N} / \mathrm{m}$ \\
\hline$l_{f}$ & Distance $C O G^{*}$ - front track & $1.56 \mathrm{~m}$ \\
\hline$l_{r}$ & Distance $C O G^{*}$ - rear track & $2.11 \mathrm{~m}$ \\
\hline$m_{s}$ & Total sprung mass & $2,032 \mathrm{Kg}$ \\
\hline$m_{u s_{1,2}}$ & Front unsprung masses & $81.5 \mathrm{Kg}$ \\
\hline$m_{u s_{3,4}}$ & Rear unsprung masses & $140 \mathrm{Kg}$ \\
\hline$t_{f}$ & Distance $C O G^{*}$-front left tire & $0.85 \mathrm{~m}$ \\
\hline$t_{r}$ & Distance $C O G^{*}$-rear left tire & $0.85 \mathrm{~m}$ \\
\hline$F_{p_{i}}$ & Passive damping forces & $i=1, \ldots, 4$ \\
\hline$F_{s a_{i}}$ & Semi-active damping forces & $i=1, \ldots, 4$ \\
\hline$F_{s_{i}}$ & Suspension forces & $i=1, \ldots, 4$ \\
\hline$F_{t_{i}}$ & Tire forces & $i=1, \ldots, 4$ \\
\hline$z_{r_{i}}^{i}$ & Ground vertical positions & \\
\hline$z_{u s_{i}}, \dot{z}_{u s_{i}}, \ddot{z}_{u}$ & Position, velocity, acc of $m_{u s_{i}}$ & \\
\hline $\begin{array}{l}z_{s_{i}}, \dot{z}_{s_{i}} \\
\quad \ddot{z}_{s_{c}}\end{array}$ & Position, velocity of $m_{s_{i}}$ & \\
\hline $\begin{array}{l}\ddot{z}_{s} . \\
\ddot{\theta}, \ddot{\phi}\end{array}$ & $\begin{array}{c}C O G^{*} \text { acceleration of } m_{s} \\
\text { Roll \& Pitch acc of } m_{s}\end{array}$ & \\
\hline
\end{tabular}

The variables and parameters of this model are described in Table I. The corresponding parameters were obtained from a commercial light-duty vehicle and $M R$ damper.

TABLE I

VERTICAL FULL VEHICLE PARAMETERS AND VARIABLES.

* COG Center Of Gravity

Problem definition. Consider a fault on a semi-active damper, e.g. an oil leakage, which induces a lack of force modeled as:

$$
\bar{F}_{s a_{i}}=\alpha F_{s a_{i}}=F_{s a_{i}}(1-\delta)=F_{s a_{i}}-F_{\delta_{i}}
$$

where $\bar{F}_{s a_{i}}$ is the faulty force given as a reduction of the nominal force and, $\alpha \in[0,1)$ is the oil leakage degree, e.g. $\alpha=0.7$ means $70 \%$ of $F_{s a_{i}}$ due to a lost force $F_{\delta_{i}}$ of $30 \%$.

The objective of the FTC strategy is to avoid a propagation of the fault effects into the whole vertical dynamics (deterioration of comfort and road holding) by designing a reconfiguration system based on the remaining healthy dampers. The main idea is to compute the required force at each corner that compensates the faulty damper effect, such that:

$\left(\begin{array}{c}\ddot{z}_{s} \\ \ddot{\theta} \\ \ddot{\phi}\end{array}\right)=f\left(\bar{F}_{s a_{i}}, F_{n_{j}}, F_{c_{j}}\right)$ for $\left\{\begin{array}{r}i \in\{1,2,3,4\} \\ j \rightarrow 3 \text { integers } \\ \text { with } j \neq i\end{array}\right.$

where, $F_{c_{j}}$ is the corresponding compensation force in the healthy damper $j$ obtained by the equilibrium analysis of the dynamics (1) to accommodate the lack of force in the faulty damper $i$ and, $F_{n_{j}}$ is the nominal damping force (suspension system free of faults). Thus, the semi-active damping force in the healthy dampers will be:

$$
F_{s a_{j}}=F_{p_{j}}+\underbrace{F_{n_{j}}+F_{c_{j}}}_{F_{I_{j}}\left(I_{n}, I_{c}\right)}
$$

where, $F_{I_{j}}\left(I_{n}, I_{c}\right)$ is obtained by an $L P V$ controller, whose design fulfills with the semi-activeness and saturation of the damper when the compensation force $F_{c_{j}}$ is added, such that the closed-loop system be:

$$
\begin{aligned}
& \dot{x}=\mathcal{A}(\rho) \cdot x+\mathcal{B}_{1} \cdot \underbrace{\left(I_{n}+I_{c}\right)}_{\mathcal{K}_{L P V}(\rho) \cdot x}+\mathcal{B}_{2} \cdot z_{r} \\
& y=\mathcal{C}(\rho) \cdot x+\mathcal{D}_{1} \cdot\left(I_{n}+I_{c}\right)+\mathcal{D}_{2} \cdot z_{r}
\end{aligned}
$$

with $\mathcal{K}_{L P V}(\rho)=\sum_{i=1}^{N} \xi_{i}(\rho) \mathcal{K}_{i}$ by appropriately choosing the gains $\mathcal{K}_{i}, i=1, \ldots, N$, such that the closed-loop system $\left(\mathcal{A}, \mathcal{B}_{1}, \mathcal{B}_{2}, \mathcal{C}, \mathcal{D}_{1}, \mathcal{D}_{2}\right)$ is asymptotically stable for all parameter variations; two varying parameters are used in the controller design: $\rho_{1}^{*}$ represents the nonlinearities of the $M R$ damper and $\rho_{2}^{*}$ is used for the actuator saturation that depends on the maximum damping force available for the compensation.

\section{FAult Detection AND Isolation}

The isolation of the faulty damper and the estimation of the damper fault $F_{\delta_{i}}$ is based on the parity-space approach because of its applicability to nonlinear systems, speed of detection, isolability property, robustness and computational complexity [4]. The aim is to synthesize a residual sensitive to the fault $F_{\delta_{i}}$ and insensitive to bounded exogenous inputs, e.g. the road profile or load transfers on the vehicle.

\section{A. Modeling of the system}

By coupling the dynamics of the full vehicle model (1), (2), (3), (5) and (6) with the faulty damper (4) and (7), a state-space representation system with 14 states is handled as:

$$
\begin{aligned}
\dot{x}_{f} & =A_{f} x_{f}+B_{f I} I+B_{f r} z_{r}+B_{f F} F_{\delta} \\
y_{f} & =C_{f} x_{f}+D_{f I} I+D_{f r} z_{r}+D_{f F} F_{\delta}
\end{aligned}
$$

where, $x_{f}=\left[z_{s_{c}}, z_{u s_{1}}, z_{u s_{2}}, z_{u s_{3}}, z_{u s_{4}}, \theta, \phi, \dot{z}_{s_{c}}, \dot{z}_{u s_{1}}, \dot{z}_{u s_{2}}\right.$, $\left.\dot{z}_{u s_{3}}, \dot{z}_{u s_{4}}, \dot{\theta}, \dot{\phi}\right]^{T}$ are the full system states, the input is $I=\left[I_{1}, I_{2}, I_{3}, I_{4}\right]^{T}, z_{r}=\left[z_{r_{1}} z_{r_{2}} z_{r_{3}}, z_{r_{4}}\right]^{T}$ is the road profile and $F_{\delta}=\left[F_{\delta_{1}}, F_{\delta_{2}}, F_{\delta_{3}}, F_{\delta_{4}}\right]^{T}$ is the fault vector. The measurement vector $y_{f}$ is given by 8 accelerometers as $y_{f}=\left[\ddot{z}_{s_{1}}, \ddot{z}_{s_{2}}, \ddot{z}_{s_{3}}, \ddot{z}_{s_{4}}, \ddot{z}_{u s_{1}}, \ddot{z}_{u s_{2}}, \ddot{z}_{u s_{3}}, \ddot{z}_{u s_{4}},\right]^{T}$. A discrete version of the system (11) with a sampling period $T_{s}$ is:

$$
\begin{aligned}
x_{f, k+1} & =A_{f d} x_{f, k}+B_{f d I} I_{k}+B_{f d r} z_{r, k}+B_{f d F} F_{\delta, k} \\
y_{f, k} & =C_{f} x_{f, k}+D_{f I} I_{k}+D_{f r} z_{r, k}+D_{f F} F_{\delta, k}
\end{aligned}
$$




\section{B. Fault detection}

The system is nonlinear due to the parameters $\rho_{1_{i}}=$ $\tanh \left[a_{1}\left(\dot{z}_{s_{i}}-\dot{z}_{u s_{i}}\right)+a_{2}\left(z_{s_{i}}-z_{u s_{i}}\right)\right]$ in the matrix $B_{f I}$ and $B_{f d I}$. Since these varying parameters appear in a linear multiplicative way, they are extracted from the system and added to the control input as:

$$
\begin{aligned}
x_{f, k+1} & =A_{f d} x_{f, k}+\bar{B}_{f d I} \underbrace{\rho_{1} I_{k}}_{\bar{I}_{k}}+B_{f d r} z_{r, k}+B_{f d F} F_{\delta, k} \\
y_{f, k} & =C_{f} x_{f, k}+\bar{D}_{f I} \rho_{1} I_{k}+D_{f r} z_{r, k}+D_{f F} F_{\delta, k}
\end{aligned}
$$

The system (13) is linear and the classical parity space approach is handled to isolate and estimate the fault.

\section{Fault isolation}

The aim of the fault isolation part is to highlight which damper is faulty. For this purpose, 4 schemes are implemented, one for each corner of the vehicle. Each fault detector has to be sensitive to the fault related to its corner.

The parity-space approach aims at extending the outputs of the system along a horizon $s$. It leads to:

$$
\begin{aligned}
& Y_{s}-G_{I} U_{s}=H x_{f, k}+G_{r} U_{r} \\
& +G_{F 1} F_{1}+G_{F 2} F_{2}+G_{F 3} F_{3}+G_{F 4} F_{4} \\
& \text { where } Y_{s}=\left[\begin{array}{c}
y_{f, k-s} \\
y_{f, k-(s-1)} \\
\vdots \\
y_{f, k}
\end{array}\right], U_{s}=\left[\begin{array}{c}
\bar{I}_{k-s} \\
\bar{I}_{k-(s-1)} \\
\vdots \\
\bar{I}_{k}
\end{array}\right] \text {, } \\
& U_{r}=\left[\begin{array}{c}
z_{r, k-s} \\
z_{r, k-(s-1)} \\
\vdots \\
z_{r, k}
\end{array}\right], F_{i}=\left[\begin{array}{c}
F_{\delta_{i}, k-s} \\
F_{\delta_{i}, k-(s-1)} \\
\vdots \\
F_{\delta_{i}, k}
\end{array}\right], H=\left[\begin{array}{c}
C_{f} \\
C_{f} A_{f d} \\
\vdots \\
C_{f} A_{f d}^{s}
\end{array}\right] \\
& \text { and } G_{i}=\left[\begin{array}{ccccc}
D_{i} & 0 & 0 & \cdots & 0 \\
C_{f} B_{i} & D_{i} & \ddots & \ddots & 0 \\
C_{f} A_{f d} B_{i} & C_{f} B_{i} & D_{i} & \ddots & 0 \\
C_{f} A_{f d}^{2} B_{i} & C_{f} A_{f d} B_{i} & \ddots & \ddots & 0 \\
\vdots & \ddots & \ddots & \ddots & \vdots \\
C_{f} A_{f d}^{s-1} B_{i} & C_{f} A_{f d}^{s-2} B_{i} & \cdots & C_{f} B_{i} & D_{i}
\end{array}\right]
\end{aligned}
$$

where, $G_{i}$ can be $G_{I}, G_{r}$ or $G_{F_{i}}$, according to the matrices $B_{i}$ and $D_{i}$ associated to the exogenous input in (13).

The presentation of the approach will be focused on the front-left corner (actuator 1) for clarity. The classical approach would consist in finding a parity matrix $W_{1}$ making sensitive the residual $r_{1, k} \triangleq W_{1}\left(Y_{s}-G_{I} U_{s}\right)$ only to the fault $F_{1}$, i.e. the matrix $W_{1}$ has to be orthogonal to the matrix $\left[\begin{array}{lllll}H & G_{r} & G_{F 2} & G_{F 3} & G_{F 4}\end{array}\right]$. Because this constraint is hard to be satisfied since this matrix contains too many columns, a non-optimal (with non perfect decoupling of the fault) solution has been considered, through the optimization problem:

$$
\text { find } W_{1} \text { subject to: }\left\{\begin{array}{l}
W_{1} G_{r}=0 \\
\max _{W_{1}} W_{1} G_{F 1} \\
\min _{W_{1}} W_{1} G_{F 2} \\
\min _{W_{1}} W_{1} G_{F 3} \\
\min _{W_{1}} W_{1} G_{F 4}
\end{array}\right.
$$

This optimization problem guaranties that $r_{1}$ is receptive to the fault, maximizing the effect of the fault $F_{\delta_{1}}$ and minimizing the effect of the others, [9], [13]. Similarly, the approach is implemented into the other three corners.

\section{Fault estimator}

The last step of the FDI procedure is the estimation of the damper fault $F_{\delta}$. At each corner, a fault estimator is designed. The main advantage of this structure is that the fault estimator is locally activated and not affected by other signals. The parity-space approach leads to:

$$
Y_{s}-G_{I} U_{s}=H x_{f, k}+G_{r} U_{r}+G_{F i} F_{i}
$$

where $i$ specifies the faulty damper. Note that in this case, the horizon $s$ could be mandatorily different in the isolation part. The classical parity matrix $W_{i, e s t}$ for estimation purpose is synthesized so that it is orthogonal to the matrix $H$ and $G_{r}$ to be insensitive to the road profile.

The residual $r_{i, e s t, k} \triangleq W_{i, e s t}\left(Y_{s}-G_{I} U_{s}\right)$ will be sensitive to any fault $F_{\delta_{i}}$, such that the parity relation $r_{i, e s t, k}=$ $W_{i, e s t} G_{F i} F_{i}$ be robust to the fault parameter $\alpha$ in eq. (7).

The fault estimator $\hat{F}_{\delta_{i}}$ is performed by inverting the relation between the residual and the fault. Indeed, it can be written, thanks to the $z$-transform formalism:

$$
\begin{aligned}
& r_{i, e s t, k}=W_{i, e s t} G_{F i} F_{i} \\
& =W_{i, e s t} G_{F i}\left[\begin{array}{lllll}
z^{-s} & z^{-(s-1)} & \ldots & z^{-1} & 1
\end{array}\right]^{T} F_{\delta_{i}, k} \\
& r_{i, e s t, k}=W G_{F i}(z) F_{\delta_{i}, k} \\
& \hat{F}_{\delta_{i}, k}=\left[W G_{F i}(z)\right]^{-1} r_{i, e s t, k}
\end{aligned}
$$

\section{Fault Tolerant Semi-Active Suspension}

When an oil leakage occurs in one of the dampers and the car is moving, the lack of damping force increases the vertical vehicle body motion. To reduce the fault propagation into the vertical dynamics, eq. (1), an extra damping force is implemented at each corner to compensate for the faulty damper and thus maintain the comfort in the vehicle.

Figure 1 shows a block diagram of the proposed FTC. Each corner has an $L P V$ controller for comfort and road holding; also, a fault estimator. Once a damper fault is detected and estimated, the reconfiguration module computes the compensation force that the healthy dampers must deliver; the $L P V$ based controller design satisfies the $M R$ damper constraints (semi-activeness and saturation).

\section{A. Fault Tolerant Control Concept}

Consider that only one actuator is faulty, e.g. the actuator 1 leading to the damping force:

$$
\bar{F}_{s a_{1}}=F_{s a_{1}}-F_{\delta_{1}}=F_{p_{1}}+F_{n_{1}}-F_{\delta_{1}}
$$

To compensate this lack of actuation, an additional force to the nominal one is demanded on the remainder of the healthy dampers, such that:

$$
F_{s a_{j, j \neq 1}}=F_{p_{j, j \neq 1}}+F_{n_{j, j \neq 1}}+F_{c_{j, j \neq 1}}
$$

where the capacity of compensation is limited by the maximum actuation value with a compromise between performance and compensation managed by the controller.

The vehicle dynamics in the $C O G$, given in (1), become: 


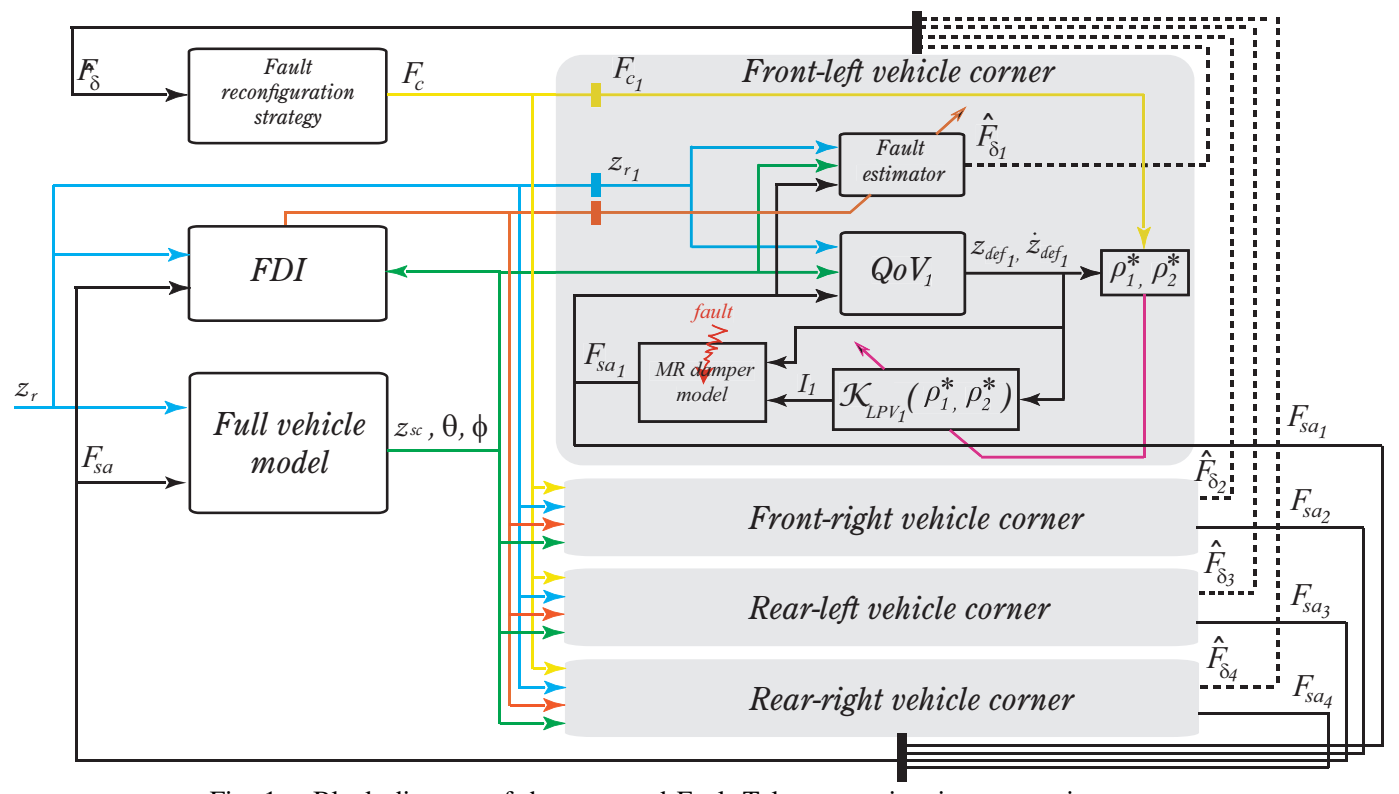

Fig. 1. Block diagram of the proposed Fault Tolerant semi-active suspension system.

$$
\begin{aligned}
m_{s} \ddot{z}_{s}= & -\left(F_{p_{1}}+F_{n_{1}}-F_{\delta_{1}}+F_{p_{2}}+F_{n_{2}}+F_{c_{2}}\right. \\
& \left.+F_{p_{3}}+F_{n_{3}}+F_{c_{3}}+F_{p_{4}}+F_{n_{4}}+F_{c_{4}}\right) \\
I_{x x} \ddot{\theta}= & \left(F_{p_{1}}+F_{n_{1}}-F_{\delta_{1}}-F_{p_{2}}-F_{n_{2}}-F_{c_{2}}\right) t_{f} \\
& +\left(F_{p_{3}}+F_{n_{3}}+F_{c_{3}}-F_{p_{4}}-F_{n_{4}}-F_{c_{4}}\right) t_{r} \\
I_{y y} \ddot{\phi}= & \left(F_{p_{4}}+F_{n_{4}}+F_{c_{4}}+F_{p_{3}}+F_{n_{3}}+F_{c_{3}}\right) l_{r} \\
& -\left(F_{p_{2}}+F_{n_{2}}+F_{c_{2}}+F_{p_{1}}+F_{n_{1}}-F_{\delta_{1}}\right) l_{f}
\end{aligned}
$$

Based on eq. (21), the compensation of $F_{\delta_{1}}$ by the healthy dampers as $F_{c_{j}, j \neq 1}$ leads to:

$$
\begin{aligned}
F_{\delta_{1}}-F_{c_{2}}-F_{c_{3}}-F_{c_{4}} & =0 \\
-t_{f} F_{\delta_{1}}-t_{f} F_{c_{2}}+t_{r} F_{c_{3}}-t_{r} F_{c_{4}} & =0 \\
l_{r} F_{c_{4}}+l_{r} F_{c_{3}}-l_{f} F_{c_{2}}+l_{f} F_{\delta_{1}} & =0
\end{aligned}
$$

which can be rewritten in matrix form as:

$$
\underbrace{\left[\begin{array}{c}
1 \\
-t_{f} \\
l_{f}
\end{array}\right]}_{N} F_{\delta_{1}}+\underbrace{\left[\begin{array}{ccc}
-1 & -1 & -1 \\
-t_{f} & t_{r} & -t_{r} \\
-l_{f} & l_{r} & l_{r}
\end{array}\right]}_{M}\left[\begin{array}{l}
F_{c_{2}} \\
F_{c_{3}} \\
F_{c_{4}}
\end{array}\right]=0
$$

$M$ is invertible since $\operatorname{det}(M)=-2 t_{r}\left(l_{f}+l_{r}\right) \neq 0$. Since $F_{\delta_{1}}$ is not measured but estimated, this allows the straightforward computation of the compensating forces $F_{c_{j, j \neq 1}}$, as:

$$
\left[\begin{array}{c}
F_{c_{2}} \\
F_{c_{3}} \\
F_{c_{4}}
\end{array}\right]=-M^{-1} N \hat{F}_{\delta_{1}}=\left[\begin{array}{c}
1 \\
t_{f} / t_{r} \\
-t_{f} / t_{r}
\end{array}\right] \hat{F}_{\delta_{1}}
$$

To expand the fault tolerance concept for other possible faulty dampers, the full matrix of compensation is given by:

$$
\left[\begin{array}{l}
F_{c_{1}} \\
F_{c_{2}} \\
F_{c_{3}} \\
F_{c_{4}}
\end{array}\right]=\left[\begin{array}{cccc}
0 & 1 & \frac{t_{r}}{t_{f}} & -\frac{t_{r}}{t_{f}} \\
1 & 0 & -\frac{t_{r}}{t_{f}} & \frac{t_{r}}{t_{f}} \\
\frac{t_{f}}{t_{r}} & -\frac{t_{f}}{t_{r}} & 0 & 1 \\
-\frac{t_{f}}{t_{r}} & \frac{t_{f}}{t_{r}} & 1 & 0
\end{array}\right]\left[\begin{array}{c}
\hat{F}_{\delta_{1}} \\
\hat{F}_{\delta_{2}} \\
\hat{F}_{\delta_{3}} \\
\hat{F}_{\delta_{4}}
\end{array}\right]
$$

\section{B. $L P V / H_{\infty}$ Control Design}

The control of the vertical dynamics is ensured by the suspension system to achieve frequency specification performances, [2]. Based on [6] that embeds into the control design the constraints of dissipativity and saturation of a semi-active damper with two scheduling parameters, here an $L P V / H_{\infty}$ controller is designed at each corner for: a) performances of comfort and road holding against road disturbances and unmodeled dynamics and, b) compensation of lack of damping force of a faulty damper.

1) Scheduling parameters: Two varying parameters are used in the $L P V$ controller synthesis for each corner: $\rho_{1}^{*}$ includes the nonlinearities of the damper and is given by,

$$
\rho_{1}^{*}=\tanh \left(a_{1} \dot{z}_{\text {def }}+a_{2} z_{\text {def }}\right) \cdot \frac{\tanh \left(\frac{I_{f}}{I_{n 0}+I_{c 0}}\right)}{\frac{I_{f}}{I_{n 0}+I_{c 0}}} \in[-1,1]
$$

where $I_{n 0}$ and $I_{c 0}$ are the average of electric currents dedicated for the nominal control and compensation. $I_{f}=I_{n}+I_{c}$ is the electric current bounded by the saturation constraint:

$$
0 \leq I_{\min }<I_{f} \leq I_{\max }
$$

$\rho_{2}^{*}$ is used directly to saturate the controller output, given by:

$$
\rho_{2}^{*}=\frac{\tanh \left(a_{1} \dot{z}_{d e f}+a_{2} z_{d e f}\right)}{a_{1} \dot{z}_{d e f}+a_{2} z_{d e f}} \cdot\left(I_{n o}+I_{c o}\right) \quad \in\left[0, \frac{I_{\max }}{2}\right]
$$

Note that there is a compromise between the control performances and the compensation because $I_{n 0}+I_{c 0}=$ $I_{\max } / 2$; the capability to compensate for a faulty damper is limited by:

$$
I_{c}=\left\{\begin{array}{lll}
I_{c}=2 \cdot I_{c 0}+I_{n 0} & \text { if } & I\left(F_{c}\right) \geq I_{c_{\max }} \\
I_{n 0}<I_{c}<I_{c_{\max }} & \text { if } & 0<I\left(F_{c}\right)<I_{c_{\max }} \\
I_{c}=I_{n 0} & \text { if } & I\left(F_{c}\right)<0
\end{array}\right.
$$

where, $I\left(F_{c}\right)=\left[F_{c} \cdot \operatorname{coth}\left(a_{1} \dot{z}_{d e f}+a_{2} z_{d e f}\right)\right] / f_{c}$ is the inverse dynamics of the $M R$ damper model, eq. (4b), that depends on the compensation force, eq. (25), and $I_{c_{\max }}=$ $2 \cdot I_{c 0}+I_{n 0}$ is the maximum electric current available for compensation. If the faulty damper requires a greater force than the one that could be generated by $I_{c_{\max }}$, the fault will not be well accommodated. In the fault free case, $I_{c 0}=0$, and the nominal controller works inside the full saturation constraint given by (27). Figure 2 shows a scheme to represent the electric current used for the compensation and its interaction with the nominal control. 


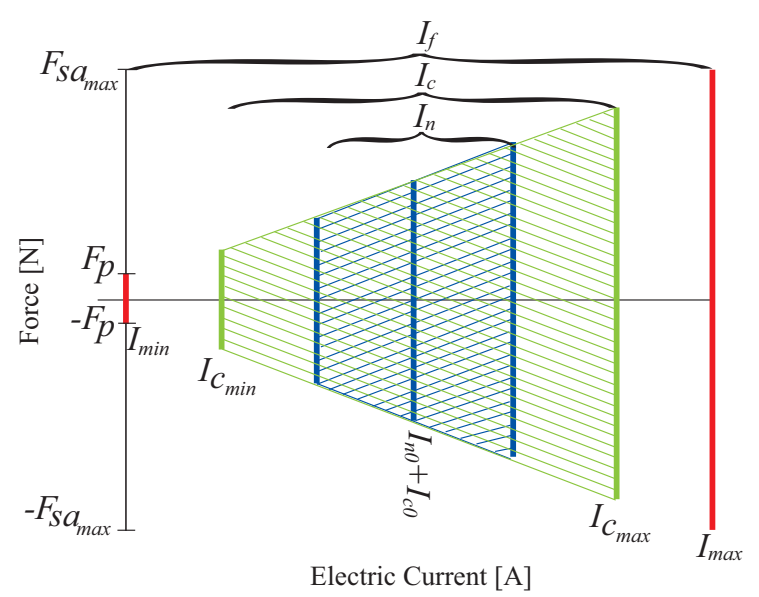

Fig. 2. Force - electric current diagram in the semi-active damper.

2) LPV model formulation: Following [6], an LPV controller of each $Q o V$ equipped with a semi-active damper is designed to handle the non-linearity of the damper model and the dissipativity constraint (represented by the maximum limit of the input electric current $I_{f}$ ). The considered model is given by [6]:

$$
\left\{\begin{array}{l}
\dot{x}_{l p v}=\mathcal{A}_{l p v}\left(\rho_{1}^{*}, \rho_{2}^{*}\right) x_{l p v}+\mathcal{B}_{1_{l p v}} u_{c}+\mathcal{B}_{2_{l p v}} z_{r} \\
y_{l p v}=\mathcal{C}_{l p v} x_{l p v}
\end{array}\right.
$$

where,

$$
\begin{gathered}
x_{l p v}=\left[\begin{array}{c}
x \\
x_{f}
\end{array}\right]^{T}, \mathcal{A}_{l p v}\left(\rho_{1}^{*}, \rho_{2}^{*}\right)=\left[\begin{array}{cc}
A+\rho_{2}^{*} B_{I 0} C_{I 0} & \rho_{1}^{*} B_{I} C_{f} \\
0_{1 \times 4} & A_{f}
\end{array}\right], \\
\mathcal{B}_{1_{l p v}}=\left[\begin{array}{c}
0_{4 \times 1} \\
B_{f}
\end{array}\right], \mathcal{B}_{2_{l p v}}=\left[\begin{array}{c}
B_{r} \\
0
\end{array}\right], \mathcal{C}_{l p v}=\left[\begin{array}{c}
C \\
0
\end{array}\right]^{T}
\end{gathered}
$$

$x$ is the state vector of a $Q o V$ with matrices $A, B_{I}, B_{I 0}, B_{r}$, $C$ and $C_{I 0}$ that include the $M R$ damper dynamics [6], with $z_{\text {def }}$ and $\dot{z}_{\text {def }}$ as output; $x_{f}, A_{f}, B_{f}, C_{f}$ are the state and matrices of a representation of the low-pass filter $W_{\text {filter }}=$ $\omega_{f} /\left(s+\omega_{f}\right)$, added to the plant to make the control input matrices parameter independent, [14].

Remark 1: The LPV model in (30) is based on the nonlinearities introduced in eq. (1d), (2), (3) and (4) for a single corner, after some mathematical transformations as in [6].

3) $L P V / H_{\infty}$ control synthesis: The extension to the method in [6] lies into the parameter $\rho_{2}^{*}$ that incorporates the damping force used to compensate the faulty damper. The control design satisfies the actuator constraints. Indeed, depending on the value of the fault, the semi-active suspension is adapted to meet the required performances. The corresponding generalized plant $\Sigma\left(\rho_{1}^{*}, \rho_{2}^{*}\right)$ is given by:

$$
\Sigma:=\left\{\begin{array}{l}
\dot{\xi}_{l p v}=\mathcal{A}_{l p v}\left(\rho_{1}^{*}, \rho_{2}^{*}\right) \xi_{l p v}+\mathcal{B}_{1_{l p v}} u_{c}+\tilde{\mathcal{B}}_{2_{l p v}} \tilde{w} \\
y_{l p v}=\mathcal{C}_{l p v} \xi_{l p v} \\
z=\mathcal{C}_{z} \xi_{l p v}+\mathcal{D}_{1_{z}} u_{c}+\mathcal{D}_{2_{z}} \tilde{w}
\end{array}\right.
$$

where $z=\left[\begin{array}{ll}z_{1} & z_{2}\end{array}\right]^{T}, \tilde{w}=W_{z_{r}}^{-1} z_{r}, y=\left[z_{\text {def }} \dot{z}_{d e f}\right]^{T}, u_{c}=u^{\mathcal{H}} \infty$ and $\xi_{l p v}$ includes the state variables of the $Q o V$ model and weighting functions, see details in [6].

\section{Problem solution}

The $L P V / \mathcal{H}_{\infty}$ controller is synthesized in the $L M I$ framework for polytopic systems; all varying parameters are bounded in $\rho_{1}^{*} \in[-1,1]$ and $\rho_{2}^{*} \in[0,3]$.
The resulting global $L P V / \mathcal{H}_{\infty}$ controller is a convex combination of the local controllers obtained by solving the set of LMIs only on each vertex of the polytope formed by the limit values of the varying parameters. The stability will be guaranteed for all trajectories of the varying parameters, even if an extra compensation force is demanded.

Remark 2: Since 2 varying parameters are used, each corner considers a polytope of 4 vertices ( 4 local controllers, more details on $L P V$ robust control design in [15]).

\section{Simulation Results}

Two scenarios have been considered to evaluate the proposed FTC in Matlab/Simulink ${ }^{\mathrm{TM}}$, by using the model (1).

\section{A. Test \#1: Without excitation of the roll angle.}

The vehicle is driven at $30 \mathrm{~km} / \mathrm{h}$. The road profile is modeled as a Chirp signal $(0.5-8 \mathrm{~Hz})$ with magnitude 0.05 $\mathrm{m}$ on the left/right sides. Because the left and right wheels are synchronized, the roll angle is not excited. The fault at $t=0 \mathrm{~s}$ is a lack of force of $50 \%(\alpha=0.5)$ on the frontleft semi-active damper, Fig. 3a. By using the proposed FDI approach described in Section III, Fig. 3b shows that the fault estimation $\hat{F}_{\delta_{1}}$ is perfectly unsensitive to the road profile (an horizon $s=1$ was used).

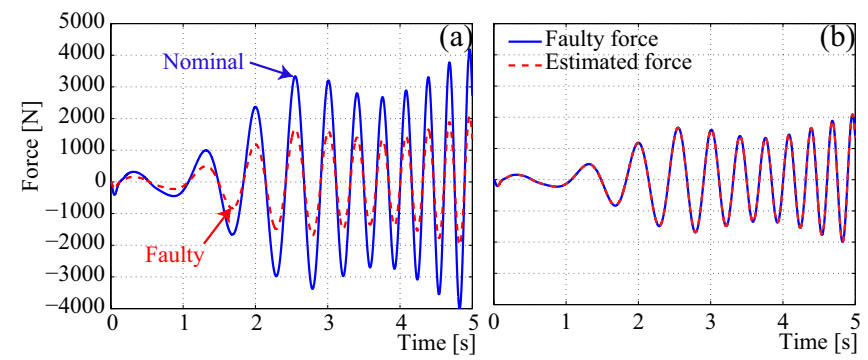

Fig. 3. Comparison between the nominal and faulty forces when $\alpha=0.5$ (a), and fault estimation performance (b).

Figure 4 shows the performance of the proposed faulttolerant semi-active suspension system depicted in Section IV versus an uncontrolled suspension (passive suspension) and a controlled suspension that does not include the fault compensation strategy (LPV nominal control); Susp. Free of Faults refers to the simulation of the $L P V / \mathcal{H}_{\infty}$ suspension control when no fault is considered (in this case the roll angle is zero). By using the Root Mean Square $(R M S)$ value of the roll angle of the vehicle as a comfort performance index, normalized w.r.t. the uncontrolled suspension, the proposed FTC improves the vehicle comfort by $82 \%$ and the nominal control by $22 \%$, i.e. the reconfiguration strategy allows an improvement of $60 \%$ of comfort, see bar graph in Fig. 4.

Figure 5a shows how the semi-active damping force increases at the front-right actuator to compensate for the missing force of the faulty damper. The semi-activeness constraint of the $M R$ damper is then ensured with the proposed FTC system. Figure $5 \mathrm{~b}$ shows that the nominal $L P V$ controller, whose performance is good when the suspension is free of faults, operates between 0 and $2 \mathrm{~A}$ without the compensation; when the compensation is used, the $L P V$ controller utilizes 


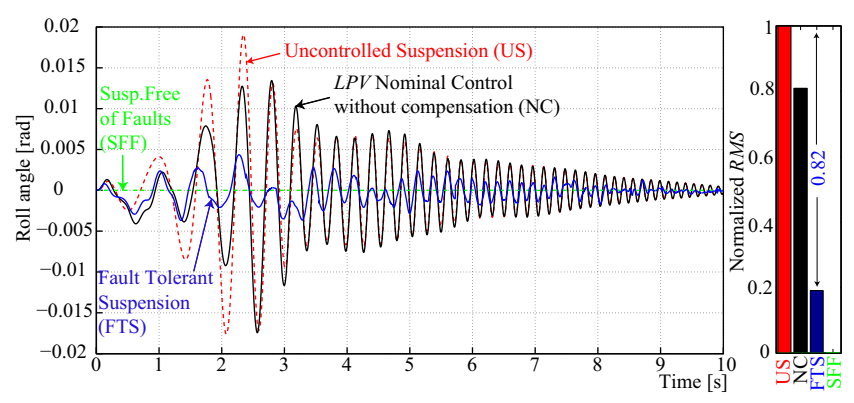

Fig. 4. Performance of the FTC in the test \#1 (left) and comparison w.r.t. the uncontrolled suspension by using a normalized $R M S$ (right).

the full range of actuation to generate more damping force and satisfies the saturation constraint of the damper (0-6 A).
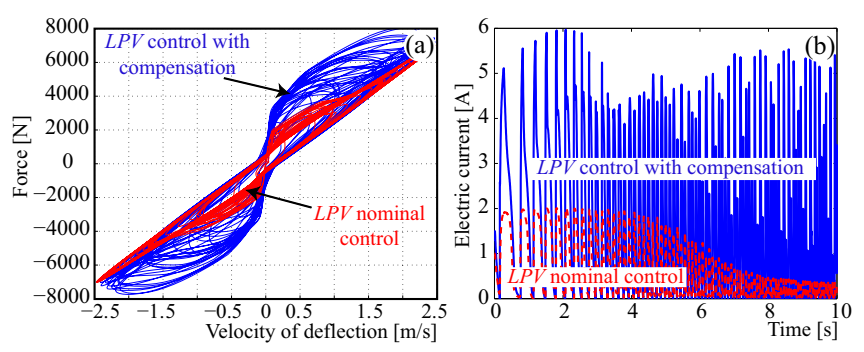

Fig. 5. Semi-active damping force in the front-right corner with and without fault compensation (a), and the corresponding controller output (b).

\section{B. Test \#2: Roll angle excitation}

The vehicle is driven at $30 \mathrm{~km} / \mathrm{h}$ in a straight way and runs over 5 sequential bumps of $5 \mathrm{~cm}$, and the left and right bumps are dephased half wheelbase in order to excite the roll angle. This test allows to analyze the performances of the $L P V$ nominal control and $L P V-F T C$ facing to an uncontrolled suspension system. The fault at $t=1.5 \mathrm{~s}$ is a lack of force of $80 \%(\alpha=0.2)$ on the front-left $M R$ damper.

Figure 6 shows that before the fault occurs $(t=1.5 \mathrm{~s})$, the roll performance of the $L P V$ controller (with or without fault compensation) is better than the passive suspension, i.e. the robust performance for comfort is $20 \%$ improved w.r.t. the passive suspension. By using the $R M S$ index, the FTC reduces the roll angle by $43 \%$ w.r.t the uncontrolled suspension and by $24 \%$ w.r.t. the controller without faulttolerance, Fig. 6.

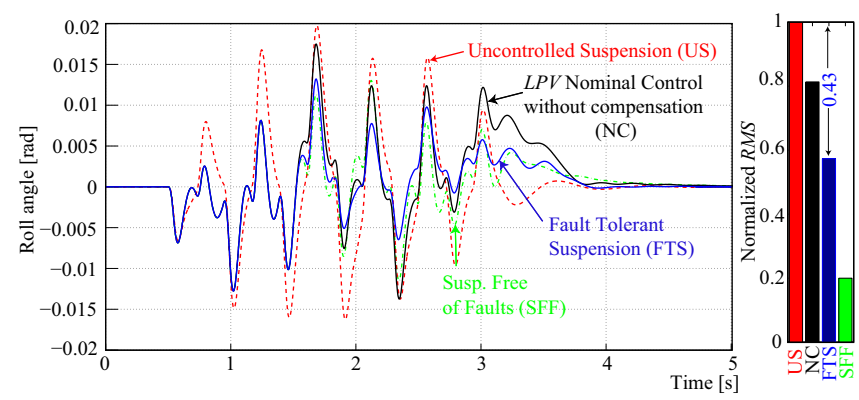

Fig. 6. Performance of the FTC in the test \#2 (left) and comparison w.r.t. the uncontrolled suspension by using a normalized RMS (right).

\section{CONCLUSION}

An effective Fault Tolerant Control (FTC) in a semi-active suspension system has been proposed for actuator faults.
When a fault occurs, such as oil leakages in a damper, the FTC system is designed to compensate for the lack of damping force by using the other three healthy shock absorbers. At a high level, a Fault Detection and Isolation module based on parity-space is used to detect and isolate the faulty damper, and a fault reconfiguration strategy computes the compensation force to be added to the healthy dampers. Each corner has a fault estimator and an $L P V$ controller for comfort and road holding; the $L P V$ control design considers the compensation force as a varying parameter in order to take into account the semi-active damper constraints.

Simulation results show the robust performance of the nominal $L P V$ controller w.r.t. a passive suspension, when the system is free of faults. When an oil leakage in the front-left damper is present, the proposed FTC system improves the comfort up to $60 \%$ and $82 \%$ w.r.t. the controlled (without compensation) and uncontrolled suspension system, respectively.

\section{REFERENCES}

[1] C. Poussot-Vassal, C. Spelta, O. Sename, S.M. Savaresi and L. Dugard, "Survey and Performance Evaluation on some Automotive Semi-Active Suspension Control Methods: A Comparative Study on a Single-Corner Model", Annual Reviews in Control, 36(1), 2012, pp: 148-160.

[2] S. Savaresi, C. Poussot-Vassal, C. Spelta, O. Sename and L. Dugard, "Semi-Active Suspension Control for Vehicles", Elsevier - Butterworth Heinemann, 2010

[3] A.L. Do, C. Spelta, S.M. Savaresi, O. Sename, L. Dugard and D. Delvecchio, "An LPV Control Approach for Comfort and Suspension Travel Improvements of Semi-Active Suspension Systems", $49^{t h}$ IEEE Conf. on Decision and Control, USA, 2010, pp: 5560-5565.

[4] Y. Zhang and J. Jiang, "Bibliographical Review on Reconfigurable Fault-tolerant Control Systems", Annual Reviews in Control, vol. 32, 2008, pp: 229-252.

[5] D. Fischer and R. Isermann, "Mechatronic Semi-Active and Active Vehicle Suspensions", Control Eng Practice, vol. 12, 2004, pp: 13531367.

[6] A.L. Do, O. Sename and L. Dugard, "LPV Modelling and Control of Semi-Active Dampers in Automotive Systems", Control of Linear Parameter Varying Systems with Applications, Mohammadpour and Scherer (Eds.), Springer, 2012, ch.15, pp: 381-411.

[7] P. Gáspár, Z. Szabó and J. Bokor, "LPV Design of Fault-tolerant Control for Road Vehicles", IEEE Conf. on Control and Fault Tolerant Systems, France, 2010, pp: 807-812.

[8] A. Chamseddine and H. Noura, "Control and Sensor Fault Tolerance of Vehicle Active Suspension", IEEE Trans. on Control Systems Tech., 16(3), 2008, pp: 416-433.

[9] J.C. Tudón-Martínez, S. Varrier, R. Morales-Menendez, R. RamirezMendoza, D. Koenig, J.J. Martinez, O. Sename, "Fault Tolerant Control with Additive Compensation for Faults in an Automotive Damper", $10^{\text {th }}$ IEEE ICNSC, France, 2013.

[10] D. Sammier, O. Sename and L. Dugard, "Skyhook and $\mathrm{H}_{\infty}$ Control of Semi-Active Vehicle Suspensions: Some Practical Aspects", Vehicle System Dynamics, vol. 39, 2003, pp: 279-308.

[11] S. Guo, S. Yang and C. Pan, "Dynamical Modeling of Magnetorheological Damper Behaviors", J. of Intell. Mater., Syst. and Struct., vol. 17, 2006, pp: 3-14.

[12] J.J. Lozoya-Santos, R. Morales-Menendez, R.A. Ramirez-Mendoza, J.C Tudón-Martínez, O. Sename and L. Dugard, "Magnetorheological Damper - An Experimental Study", J. of Intelligent Mater. Syst. and Struct., vol. 23, 2012, pp: 1213-1232

[13] S. Varrier, D. Koenig and J.J. Martinez, "Robust Fault Detection for Vehicle Lateral Dynamics", 51 ${ }^{\text {st }}$ IEEE Conf. on Decision and Control, USA, 2012, pp: 4366-4371.

[14] C. Poussot-Vassal, O. Sename, L. Dugard, P. Gáspár, Z. Szabó and J. Bokor, "A New Semi-Active Suspension Control Strategy through LPV Technique", Control Eng. Practice, vol. 16, 2008, pp: 1519-1534.

[15] C. Scherer, P. Gahinet and M. Chilali, "Multiobjective OutputFeedback Control Via LMI Optimization", IEEE Trans. on Automatic Control, 42(7), 1997, pp: 896-911. 